\title{
INSERCIÓN LABORAL EN EL AGRO COSTARRICENSE EL CASO DE LOS NICARAGÜENSES
}

\section{Eduardo Baumeister}

\section{Resumen}

Desde 1980, el agro de Costa Rica sufrió cambios que expandieron la agroexportación. De manera paralela, crecieron el turismo y otras actividades no agrícolas. En Nicaragua, por su parte, las actividades agrícolas de exportación decayeron y, por tanto, también la demanda de mano de obra. A partir de la década del noventa, se ampliaron las migraciones de nicaragüenses hacia Costa Rica, creándose un modelo de articulación de tipo sur-sur, muy diferente al del resto de América Central, centrado en migrar a Estados Unidos. Los salarios agrícolas en Costa Rica son más elevados que en Nicaragua, sin embargo, una parte importante de los nicaragüenses trabajan de manera informal, con salarios inferiores a los de los costarricenses y en condiciones de pobreza multidimensional.

Palabras clave: migración laboral agrícola sur-sur, condiciones de los trabajadores agrícolas, consecuencias sociales de la emigración internacional.

\section{Abstract}

Labor insertion in Costa Rican agriculture. The case of the Nicaraguans

Since 1980, the agriculture of Costa Rica underwent changes that expanded agro-exports. In parallel, tourism and other non-agricultural activities spread. In Nicaragua, agricultural export activities declined and, therefore, the demand for labor. Beginning the nineties, Nicaraguan migrations to Costa Rica expanded, creating a South-South model of articulation, very different from the rest of Central America, focused on migrating to the United States. Agricultural wages in Costa Rica are higher than in Nicaragua; however, an important part of Nicaraguans work informally, with lower wages than Costa Ricans, and in conditions of multidimensional poverty.

Keywords: South-South labour migration, condition of agricultural workers, social consequences of international emigration.

Eduardo Baumeister: Doctor en Ciencias Sociales por la Universidad de Nijmegen, Holanda. Investigador asociado en el Instituto Nitlapan de la Universidad Centroamericana. Trabaja en temas agrarios y migratorios en los países de América Central.

ORCID iD: 0000-0002-9060-6916

Email: eduardobaumeisterb@gmail.com 


\section{Introducción ${ }^{1}$}

Costa Rica y Nicaragua son países vecinos que tienen muchos puntos comunes en su historia política y en las formas de insertarse en el mercado mundial. Sin embargo, desde fines del siglo pasado, las distancias económicas y sociales aumentaron notablemente. En la actualidad, por ejemplo, en el ranking del índice de desarrollo humano mundial de 2019, Costa Rica ocupa la posición 68 y Nicaragua, la 126, en una escala que mide a 189 países (PNUD, 2019). Los cambios agrarios en ambos territorios fueron diferentes $\mathrm{y}$, a partir de los años noventa del siglo pasado, se desarrolló un proceso de migración de mano de obra nicaragüense hacia la agricultura y otros sectores de Costa Rica.

El presente artículo analiza los cambios agrarios, demográficos y ocupacionales en ambos países, incluyendo las modalidades de inserción de la fuerza de trabajo agrícola nicaragüense en el agro costarricense.

La relevancia de abordar estos temas se sustenta en dos razones principales:

a. En primer lugar, la importante migración de nicaragüenses a Costa Rica constituye una modalidad muy diferente de la que atraviesa el resto de los países de Centroamérica y el propio México, cuyo destino principal es Estados Unidos. Mientras esta es la típica movilidad sur-norte, la de Nicaragua y Costa Rica se encuadra dentro de un esquema sur-sur de migraciones internacionales. ${ }^{2}$

b. Pese a que más de tres cuartas partes de la población costarricense vive en zonas urbanas y existe un incipiente sector productivo y de servicios no agrarios, las actividades agrícolas mantienen una importancia significativa, particularmente en el sector exportador. Tanto así es que sus exportaciones agrarias son muy superiores a las de Nicaragua, que sigue siendo un país principalmente de base

1 Parcialmente basado en Baumeister (2021).

2 En América Latina otros ejemplos de migraciones con destino a la agricultura de tipo sur-sur son las haitianas a República Dominicana, las bolivianas a la Argentina y las guatemaltecas al sur de México. 
agropecuaria; aunque el empleo agrícola costarricense conserva un peso importante en comparación con el conjunto de América Latina. ${ }^{3}$

Partimos de la hipótesis de que, en el caso de Costa Rica, la desigualdad en el acceso a la tierra y al conjunto del capital productivo, si bien tiene una base histórica, se profundiza a causa de un proceso de diversificación agrícola para la exportación, particularmente en zonas alejadas del Valle Central. ${ }^{4}$ En esta área se cultiva buena parte de la piña, la caña de azúcar y la palma africana (palma aceitera), y se amplía el crecimiento bananero y la ganadería vacuna, junto con una expansión de actividades no agrícolas, como el turismo, tanto en la costa pacífica como en la atlántica, las maquilas, que incluyen productos de mayor complejidad tecnológica, y los servicios, que fomentan un intenso proceso de urbanización. ${ }^{5}$ En Nicaragua, la desigualdad histórica en la distribución de la tierra —más allá de los intentos parciales de reforma agraria en la década del ochenta - genera que una parte importante de la población rural tenga que buscar espacios laborales fuera de las zonas agrarias del país, lo que incluye la migración permanente o temporal a Costa Rica.

El artículo está organizado en seis apartados, además de esta introducción. En el primero se tratan rasgos básicos del modelo agrario costarricense, tanto algunos más continuos como los contemporáneos. En el segundo se abordan los cambios de la estructura agraria de Nicaragua y el proceso estructural que permite entender la inserción de los nicaragüenses en el agro de Costa Rica. En el tercer apartado se presentan algunos rasgos comparativos

3 Algunos cálculos propios que suman costarricenses, extranjeros, formales e informales permanentes y temporales, incluyendo microempresas de servicios a la producción y las actividades de procesamiento agroindustrial (Pomareda, 2018), permiten estimar el peso ocupacional del sector por encima de un $20 \%$ del total de ocupados en el país; mientras que los ocupados en la agricultura en América Latina para años recientes, según la Organización Internacional del Trabajo (OIT) (2021) no llegan a un 14\% de los ocupados.

$4 \quad$ En el Mapa 1 se ven las principales regiones de Costa Rica. La central se caracteriza por la producción de café, por la mayor concentración de población y por ser asiento de la mayor parte de las actividades industriales. La región Chorotega, al noroeste, con frontera con Nicaragua, se caracteriza por la producción de caña de azúcar, arroz, melón y naranja y por ser la principal zona turística de playa. La región Pacífico central, en el centro-oeste, se caracteriza por la producción de palma, mangos, actividades turísticas, y producción pesquera. La región Brunca, en el sureste en dirección hacia Panamá, produce palma, café y piña. La región Huetar atlántica, con costas sobre este océano, está caracterizada por la producción de banano y piña. Y la Huetar norte, con amplia frontera fluvial con Nicaragua, es asiento de la mayor producción de piña y tubérculos.

5 La diversificación agrícola, iniciada a mediados de los años ochenta del siglo XX, y con más intensidad luego de 1990, representada por rubros como piña y palma aceitera, entre otros, ha tenido una base productiva con mayor peso de productores de mayor escala, incluyendo empresas trasnacionales, aunque hay también segmentos de pequeños y medianos; pero el control del procesamiento y la comercialización externa/interna muestran una concentración económica significativa. Hay que tener en cuenta que estos nuevos rubros requieren mayores inversiones de capital, tanto en el proceso productivo propiamente agrícola como en la transformación agroindustrial y el transporte. 
de las estructuras agrarias de Costa Rica y Nicaragua. En el cuarto se abordan las características de la fuerza de trabajo agrícola nicaragüense en Costa Rica. En el quinto se hace un análisis preliminar de las consecuencias del COVID-19 y las labores agrícolas en Costa Rica, particularmente en el café, el principal demandante de mano de obra temporal. Y, finalmente, en el sexto se presentan los comentarios finales.

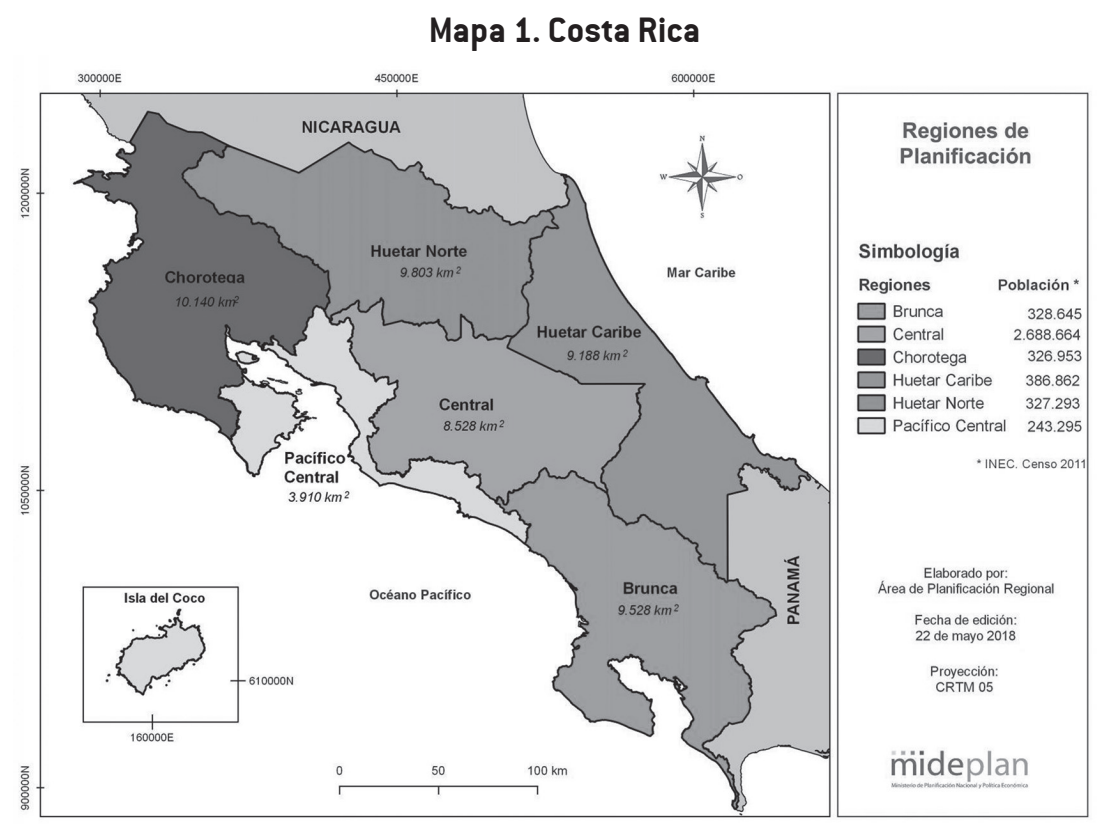

Fuente: MIDEPLAN, 2018.

\section{Factores asociados al modelo agrario costarricense}

En este apartado se presentan los factores que pueden ayudar a entender las peculiaridades del desarrollo agrario de Costa Rica. Las preguntas apuntan a lograr dos objetivos: por un lado, entender el caso agrario costarricense y, por otro, analizar los condicionantes estructurales que permiten comprender la inserción laboral de los nicaragüenses en esa agricultura.

\section{Configuración histórica}

Para comprender la configuración actual de la agricultura costarricense, se requiere analizar los factores que, desde su origen, en el período colonial, han influido en su evolución. En primer lugar, el poblamiento español fue importante en el Valle Central, una zona relativamente pequeña que com- 
prende las partes más pobladas de las provincias de San José, Cartago, Heredia y Alajuela. ${ }^{6}$ En esta región hay buenas condiciones para la producción agrícola y fue poblada por un grupo humano relativamente reducido que no encontró asentamientos indígenas importantes. La agricultura que se desarrolló inicialmente fue de tipo familiar, en pequeña escala; se cultivaron granos básicos y luego el café, desde el siglo XIX, que empleaba a un segmento ocupacional de trabajadores asalariados temporales que habitaban en zonas cercanas a las plantaciones de café. ${ }^{7}$ Sin embargo, hubo desde las primeras décadas del siglo XIX un grupo económico distinto, dedicado al beneficiado, financiamiento y comercialización externa del café, que rápidamente fue diferenciándose por su capacidad de acumulación y control del proceso productivo desde la esfera de la circulación.

La amplia frontera agrícola permitió el paulatino poblamiento de zonas más alejadas del núcleo del Valle Central en distintas direcciones. Se conformó la actividad ganadera en la zona de Guanacaste, cercana a Nicaragua, con productores de mayor tamaño, la actividad bananera en la costa atlántica, con empresas trasnacionales y empresarios nacionales y, más tarde, en el Pacífico sur (véase el Mapa 1).

La configuración social incluyó estratos relativamente amplios de pequeños y medianos agricultores, y una élite económica nacional y extranjera más concentrada en la esfera de la transformación y comercialización de productos como café y con presencia directa en la producción en rubros como banano, azúcar y ganadería vacuna. Desde la década del cincuenta hasta los años ochenta del siglo pasado, el Estado intervino en la agricultura respaldando algunas demandas económicas de los productores de café con créditos, asistencia técnica, apoyos a la formación de cooperativas y regulando, en parte, los precios pagados por los exportadores. Los productores de granos básicos para el mercado interno también contaron con protección arancelaria, precios de sustentación y acceso a la banca estatal. Esta dinámica existió, aproximadamente, hasta mediados de los años ochenta del siglo pasado. ${ }^{8}$

\section{Cambios agrarios a partir de 1980}

A mediados de los años ochenta del siglo pasado, se inició una política de ajuste estructural que hizo énfasis en los cultivos no tradicionales de exportación; redujo fuertemente la producción de granos básicos; buscó la reorienta-

6 Presenta una temperatura media cercana a los 22 grados, una altura media con respecto al nivel del mar de 1400 metros, con un período lluvioso que normalmente se extiende entre mayo y octubre, y un período de muy pocas precipitaciones entre noviembre y abril.

7 Para 1950 se estimaba que en el Valle Central alrededor del 56\% de los ocupados en la agricultura eran trabajadores asalariados (Instituto de Investigaciones en Ciencias Económicas (2007, cuadro 142, gentilmente proporcionado por el profesor Nelson Arroyo Blanco). 
ción de la ganadería vacuna para que se concentrase más en la producción de leche y sus derivados, y, en menor medida, en carne; y disminuyó el crédito a la producción agropecuaria y la asistencia técnica que anteriormente brindaba el Estado.

Entre 1950 y 1984, la expansión de la frontera agrícola hacia el norte, este y sur del país generó un aumento de la población rural, en general, y también del número de pequeñas explotaciones, muchas veces en condiciones precarias. ${ }^{9}$ En 1984, se censó un total de 102.000 explotaciones, mientras que en 2014 el número se contrajo a 93.000. El factor más importante de esta reducción fueron los cambios en el uso del suelo, tal como puede verse en el Cuadro 1, al reducirse la superficie de pastos en cerca de un millón de hectáreas. Este hecho es explicable por los cambios en la orientación de la ganadería vacuna, que llevaron a la disminución de las actividades de ganadería de carne y dieron mayor importancia a la de leche. El total de ganado en 1984 era de 2,4 millones de cabezas; en 2017, se estimó en 1,4 millones (FAO, s. f. a). Por otro lado, entre 1984 y 2014, el área de bosques se incrementó, principalmente como consecuencia de la reducción de los pastos. ${ }^{10}$

\section{Cuadro 1. Cambios en el uso del suelo y evolución del hato ganadero en Costa Rica, 1984-2017 [miles de hectáreas]}

\begin{tabular}{ccc}
\hline Uso del suelo & 1984 & 2017 \\
\hline Cultivos anuales & 283 & 203 \\
\hline Cultivos permanentes & 235 & 319 \\
\hline Pastos & 2.230 & 1.200 \\
\hline Área de bosques & 1.328 & 2.657 \\
\hline
\end{tabular}

Fuente: para los usos agrícolas, FAO (s. f. a); para el área de bosques, Oviedo et al. (2015, p. 68); y cálculos propios.

Transformación de la estructura productiva tradicional

Hacia fines de la década del ochenta, y particularmente a partir de la década del noventa, surgieron nuevos productos de exportación. Se destacan rubros como piña, flores, follajes, palma aceitera y otras frutas (melón, sandía y

9 Entre 1963 y 1985 , se estima que diferentes grupos de campesinos tomaron por su cuenta una superficie equivalente al 27\% de la superficie en fincas de 1984 (Picado y Botella, 2017, y estimaciones propias sobre los alcances de estas ocupaciones de tierras).

10 La ampliación del área de bosques se hizo principalmente por regeneración natural y, en parte, por plantaciones forestales. Los dueños de bosques han recibido transferencias por la contribución al mejoramiento del medioambiente. En general, estos bosques y las transferencias generadas se han concentrado en las fincas de mayor tamaño (Picado y Botella, 2017). 
cítricos); se redujeron fuertemente las siembras de maíz y frijol, y fueron reemplazadas por importaciones masivas ${ }^{11}$ (véase el Cuadro 2 ).

\section{Cuadro 2. Áreas de los principales cultivos en Costa Rica, 1984-2014 (miles de hectáreas]}

\begin{tabular}{cccc}
\hline & 1984 & 2014 & Diferencia \\
\hline $\begin{array}{c}\text { Granos básicos (maíz, frijol, arroz y sorgo) } \\
\text { Cultivos tradicionales (bananos, café, caña de azúcar y } \\
\text { plátanos) }\end{array}$ & 141 & 56 & -85 \\
\hline Nuevos productos (piña, palma, melón, yuca y naranjas) & 26 & 151 & 42 \\
\hline Total & 325 & 408 & 83 \\
\hline
\end{tabular}

Fuente: FAO [s. f. a) y cálculos propios.

Sin embargo, algunas intervenciones del Estado, forjadas entre 1950 y 1990, se mantienen hasta el presente en distinto grado, particularmente la participación en la fijación del precio del café pagado a los productores y la existencia de precios básicos al productor de banano de exportación. Esta es una diferencia en comparación con lo ocurrido en los demás países de la región, donde la intervención del Estado para ayudar a los productores fue de menor intensidad o se redujo de manera significativa.

\section{Establecimiento de precios al productor}

En algunos rubros, como el café y el banano de exportación, el Estado sigue teniendo cierto grado de intermediación en la fijación de los precios pagados a los productores directos.

En 1961, se dictó la Ley 2762 (Costa Rica, Poder Legislativo, 1961), que sigue rigiendo las relaciones económicas entre productores, beneficiadores y exportadores de café. Sobre la base de los precios internacionales y nacionales de este producto, se establecen los márgenes de ingresos que reciben por ley los diversos actores, una vez que se deducen los gastos de procesamiento y comercialización. La conjunción entre esta política de regulación del precio al productor y las promociones comerciales de Costa Rica - que trata de posicionar al país y a sus productos en el comercio internacional alrededor del concepto de "marca país" - incide en que el precio del café costarricense sea uno de los más elevados a nivel mundial.

En la categoría de cafés suaves, en América Latina, durante el período

11 En 1984, existían 35.411 explotaciones de maíz y en 2014 se registraron 17.756; las de frijol pasaron de 25.923 a 14.707 en el mismo período; y las de arroz, de 15.205 a 4467 (Picado y Botella, 2017). 
2016-2018, el promedio del pago por 100 libras de café fue de USD 121 para los productores colombianos, de USD 134 para los costarricenses, de USD 84 para los salvadoreños, de USD 131 para los guatemaltecos, de USD 89 para los hondureños y de USD 79 para los peruanos (ICO, s. f.).

En el caso del banano, coexisten dos tipos de grandes productores: los nacionales y las empresas extranjeras, que se reparten la producción aproximadamente en partes iguales. La Ley 7147 (Costa Rica, Poder Legislativo, 1990), de la Corporación Bananera Nacional Sociedad Anónima, establece que el Estado puede: "Recomendar los precios mínimos de referencia para la compra y la venta del banano en la modalidad FOB (libre a bordo), los cuales podrán ser establecidos mediante decreto ejecutivo" (Costa Rica, Poder Legislativo, 1990). En determinadas coyunturas, esta norma permite obtener un precio mínimo de venta a los productores nacionales que comercian con las empresas internacionales, disposición vigente en la actualidad. ${ }^{12}$

En otros casos, como la piña, si bien no existen precios mínimos a favor de los productores, la combinación de disposiciones mediante las que participa el Estado, como la creación de la marca país, amplía la capacidad de negociación de los productores en el mercado internacional. El precio de la piña de Costa Rica es superior al de sus principales competidores. En 2017, el precio de exportación de la tonelada de piña de Filipinas, el segundo exportador mundial luego de Costa Rica, fue de USD 406, mientras que la tonelada de piña de Costa Rica costó USD 484 dólares (FAO, s. f. a, y cálculos propios).

\section{La persistencia de las exportaciones de origen agrario}

Aunque Costa Rica es un país crecientemente urbano con una economía diversificada, las exportaciones agropecuarias y agroindustriales siguen siendo muy importantes. En el contexto de Centroamérica, las exportaciones agrarias de Costa Rica ocupan la segunda posición luego de Guatemala, cuya población rural y dedicada a la agricultura sigue teniendo un fuerte peso. En Costa Rica, las exportaciones agrícolas son importantes en términos absolutos, pero pesan también en el total de las exportaciones de mercancías, como puede verse en el Cuadro 3.

12 El banano también es considerado parte de la marca país, se regula bajo las leyes 4895 y 7147. Buena parte de las exportaciones son realizadas por empresas transnacionales; sin embargo, algunos productores nacionales logran exportar directamente a Europa. 


\section{Cuadro 3. Exportaciones agropecuarias de Centroamérica (en millones de dólares corrientes], 2017}

\begin{tabular}{ccc}
\hline País & $\begin{array}{c}\text { Exportaciones } \\
\text { agropecuarias }\end{array}$ & $\begin{array}{c}\text { Porcentaje del agro en el total de mercancías } \\
\text { exportadas }\end{array}$ \\
\hline Guatemala & 5.351 & $53,5 \%$ \\
\hline Costa Rica & 4.911 & $51,4 \%$ \\
\hline Honduras & 2.680 & $30,9 \%$ \\
\hline Nicaragua & 2.142 & $41,4 \%$ \\
\hline El Salvador & 988 & $17,1 \%$ \\
\hline
\end{tabular}

Fuente: FAO (s. f. a) y cálculos propios.

\section{Alto consumo de plaguicidas en la agricultura}

El proceso de expansión de rubros nuevos ha estado asociado de manera negativa con un fuerte incremento del uso de plaguicidas. De acuerdo con distintas fuentes, Costa Rica es uno de los países con mayor consumo de plaguicidas por hectárea cultivada del mundo. ${ }^{13}$

Esto se explica por el tipo de tecnologías utilizadas en los nuevos productos y por la importante reducción de los cultivos más típicamente alimenticios de Centroamérica, como el maíz y el frijol, que en los otros países ocupan mucha área y tienen paquetes tecnológicos de insumos menos intensivos. ${ }^{14} \mathrm{Si}$ bien Costa Rica presenta un perfil de alta utilización de plaguicidas, es importante observar su capacidad de presentarse como un país "verde", por cuatro razones principales:

a. la recuperación de su área de bosques a los niveles de los años inmediatamente posteriores a la Segunda Guerra Mundial, un nivel difícil de encontrar en otros países de América Latina;

b. la existencia de áreas protegidas, que permiten un mejor manejo de recursos naturales;

c. una importante generación de energía a partir de recursos hidroeléctricos; y

d. la estabilidad institucional del país, que resulta una muy buena presentación para su perfil turístico y para la consideración del país como "verde" desde el punto de vista ambiental.

13 Datos para 2018 lo ubican como uno de los tres países del mundo más demandantes de plaguicidas por hectárea (FAO, s. f. a).

14 Costa Rica importa casi todo el maíz y buena parte del frijol que consume anualmente. En el período 2015-2017, el país importó el 85,5\% de los cereales (FAO, s. f. a). 


\section{Estructura agraria de Nicaragua e inserción de los trabajadores nicaragüenses en Costa Rica}

Nicaragua ha vivido intensos cambios políticos, económicos y agrarios entre fines de la década del setenta hasta el presente, los que han traído consecuencias importantes sobre los hogares rurales. Históricamente, el país ha mostrado el patrón tradicional latinoamericano: un significativo peso de las grandes haciendas y un núcleo mayoritario de sectores campesinos e indígenas con mucho menor acceso a la tierra y con altos niveles de semiproletarización, al ir insertándose en actividades de los cultivos de exportación, proceso que continúa hasta el presente. En este apartado, se analiza la situación anterior a la reforma agraria ejecutada entre 1979 y 1990, los resultados alcanzados por esta y la situación actual.

\section{Alcances y limitaciones de la reforma agraria}

El principal período de la reforma agraria en Nicaragua se dio entre 1979 y 1990. Esta llegó a intervenir a cerca de un $28 \%$ de la superficie en fincas, creó empresas manejadas por el Estado y cooperativas de corte colectivo, y benefició también, pero con menor énfasis, a campesinos individuales. Durante este período, se estima que un $24 \%$ de las familias dedicadas a la agricultura tuvo acceso a la tierra, ya sea mediante formas colectivas o de manera individual (Baumeister, 1998, pp. 185-189).

Esta reforma agraria puede describirse como relativamente profunda por el peso de las tierras reformadas, que fueron una parte sustantiva de las fincas de mayor dimensión: arriba de 500 manzanas (mz.), equivalentes a 350 hectáreas (ha) de extensión total. No obstante, abarcó a menos de la cuarta parte de las familias dedicadas a la agricultura, compuesta mayoritariamente por minifundistas y asalariados sin tierra. Además, la gran mayoría de beneficiarios fueron hombres, mientras que prácticamente se excluyó a las mujeres del proceso de entrega de tierras. Estas características constituyen algunas de las principales limitaciones de la reforma agraria nicaragüense, como puede verse en el Cuadro 4, al finalizar la parte principal del proceso de redistribución de la tierra.

Con los cambios políticos iniciados en abril de 1990, particularmente cuando se abrió la posibilidad de que antiguos dueños de tierras afectadas por la reforma agraria reclamaran su derecho a recuperar la tierra o iniciar un proceso de indemnización, la estructura agraria existente experimentó modificaciones importantes. En primer lugar, el área estatal y las cooperativas con tenencia colectiva de la tierra se transformaron rápidamente en tierras privatizadas.

El área estatal, conocida como área propiedad del pueblo, en buena medida, terminó en manos de grandes propietarios. Por el contrario, las áreas pertenecientes a las cooperativas colectivas, en general, quedaron 
en manos de algunos de los antiguos socios de estas, ya no como áreas colectivas, sino como tierras privadas, en su mayoría por procesos de compraventa entre los propios socios o adquiridas por pequeños y medianos agricultores cercanos a estas unidades de producción. El resultado de estos importantes cambios fueron movimientos de tenencia de tierra entre distintos estratos. ${ }^{15}$

Por otro lado, los estratos inferiores a $35 \mathrm{ha}$, en el marco de una agricultura fuertemente extensiva como la nicaragüense son considerados parte de la llamada agricultura familiar; se sustentan en el trabajo del productor o productora con el concurso de sus familiares inmediatos y con la posible contratación de mano de obra temporal en algunos momentos del año agrícola. Este tipo de propiedad tenía un 17,5\% de la tierra antes de la reforma agraria; en 2011, pasó a tener un 25,5\% de la tierra en fincas. En menor medida, también se incrementó el estrato de agricultores medianos, quienes tienen propiedades de entre 141 ha y 350 ha, están insertos en la agricultura comercial y contratan mucha mano de obra.

Antes de la reforma agraria, las familias sin acceso directo a la tierra que trabajaban básicamente como asalariados agrícolas representaban un 37\% de las dedicadas a la agricultura. En 1989, a fines del período de la reforma, eran un $22 \%$ de este grupo, debido al aumento de las familias que accedieron, de algún modo, a la tierra.

Los datos del Censo Agropecuario de 2011, el último disponible, reflejan que las familias agrícolas sin tierra representaban cerca de un $36 \%$ de este grupo, un peso relativo mucho mayor que en 1989 y muy similar al observado en 1971. Este porcentaje está conformado tanto por trabajadores fijos como por trabajadores contratados la mayor parte del año agrícola en distintas unidades de producción, según los requerimientos estacionales de las labores agropecuarias.

Por su parte, el grupo de familias con parcelas menores a $10 \mathrm{mz}$. pasó de controlar un 2,1\% de la tierra en 1971 a un 5,6\% en 2011. Ello se explica por el acceso a la tierra mediante la reforma agraria y por las posteriores parcelaciones de las cooperativas con tenencia colectiva de la tierra y las divisiones de las fincas de más de $10 \mathrm{mz}$., como consecuencia de los procesos de herencia. Sin embargo, el aumento también se relaciona con las ventas parciales de tierras, que redujeron el tamaño medio de parcelas de mayor extensión (Baumeister y Marti i Puig, 2018, p. 297). La venta de tierras para cubrir necesidades se ha detectado en el monitoreo de las dinámicas locales de la tierra realizado por las organizaciones que forman parte de la Estrategia

15 En el Pacífico de Nicaragua, donde existían relativamente más unidades de producción estatales y cooperativas colectivas, durante la vigencia de la reforma agraria se observaron procesos importantes de privatización de tierras por parte de grandes productores. Estos ampliaron, principalmente, las áreas de caña de azúcar y maní, y la franja costera dedicada al turismo de playa (hoteles, condominios y viviendas de segunda residencia). 
Nacional de Involucramiento (ENI) (s. f.) para el acceso de los pobres a la tierra en Nicaragua. ${ }^{16}$

En cambio, el grupo de más de $10 \mathrm{mz}$. es muy heterogéneo en su composición; pierde peso en términos de familias agrícolas, pero no en la proporción de tierra controlada, particularmente por los estratos intermedios -entre 10 y $200 \mathrm{mz}$., es decir, entre 7 y 140 ha-, que aumentó de $40 \%$ a 56\% entre 1971 y 2011.

En síntesis, con una visión de largo plazo, se puede afirmar que la reforma agraria cambió la estructura de la tenencia de la tierra: redujo el peso del grupo más grande de los propietarios, situación que se ha mantenido en buena parte entre 1990 y la actualidad. Sin embargo, la ampliación de la frontera agrícola ha permitido que el número absoluto de tierras controladas por estratos medianos y grandes creciera desde 2011 hasta hoy. Este avance de tierras agrarias se ha producido en las regiones Atlántico norte, Atlántico sur y río San Juan, mediante la expansión ganadera, palmera y cafetalera, específicamente con la variedad robusta.

De manera aproximada — debido a las diversas fuentes utilizadas para las estimaciones-, al analizar los datos de varias décadas se pueden hacer las siguientes observaciones:

a. Las familias sin tierra, es decir, aquellas cuyos miembros trabajan en la agricultura, pero no tienen acceso directo a la tierra, representaban un $37 \%$ de las familias dedicadas a la agricultura hacia 1971. Estas descendieron a un $22 \%$ hacia fines de la década del ochenta, como consecuencia de las acciones de la reforma agraria, que dieron acceso a la tierra a familias que anteriormente no la tenían. Hacia 2011, volvieron a representar un porcentaje cercano al que tenían en 1971, debido al regreso a manos de propietarios tradicionales de muchas fincas que habían sido expropiadas durante la reforma agraria y al crecimiento, desde finales de la década del noventa, del trabajo asalariado en la agricultura, particularmente en la ganadería vacuna. ${ }^{17}$ Por ejemplo, entre 2001 y 2011, los trabajadores agrícolas contratados, en buena medida temporales, crecieron un $40 \%$ (cálculos propios basados en censos agropecuarios de $2001 \mathrm{y}$ del 2011), mientras que, en ese mismo período, la población rural -

16 La ENI es una plataforma multiactoral promovida por miembros de la Coalición Internacional para el Acceso a la Tierra (ILC). En Nicaragua, está integrada por catorce organizaciones.

17 El número de cabezas de ganado vacuno creció un 75\% entre 1985 y 2011 según datos de FAO (s. f. a). Esto creó mucho empleo asalariado permanente y temporal, particularmente en las fincas más dedicadas a la lechería que requerían personal los 365 días del año en las actividades de ordeño y manejo de terneros, y trabajo temporal para el cuidado de los pastos y la infraestructura. 
que es el tipo de población de la mayor parte de los trabajadores agrícolas- creció un poco menos de un $11 \%$. Este es un claro indicio de la presión hacia el trabajo asalariado para la población rural de Nicaragua. ${ }^{18}$

b. Las familias consideradas minifundistas, que en el contexto agrario de Nicaragua pueden incluir a las explotaciones de menos de $10 \mathrm{mz}$. (aproximadamente $7 \mathrm{ha}$ ), incrementaron su peso relativo debido a tres factores principales: primero, la frecuente fragmentación de las explotaciones debido a los procesos hereditarios; segundo, la parcelación de las cooperativas de tenencia colectiva, que habían recibido tierras de la reforma agraria; tercero, la ampliación de la superficie trabajada que se encontraba en abandono durante el conflicto armado interno acontecido entre 1981 y 1990.

c. El sector de familias con más de $10 \mathrm{mz}$. es, por definición, un grupo muy heterogéneo. Debe asumirse de esa manera, porque en las décadas del ochenta y el noventa no se efectuó ningún censo agropecuario que permitiera estratificar adecuadamente a las familias productoras agropecuarias. Por efecto de las acciones de la reforma agraria, el número de explotaciones de este sector se redujo entre 1971 y 2011, sobre todo en los predios de mayor extensión.

d. A partir de 1990, el sector de las familias directamente beneficiarias de la reforma agraria desapareció como parte de estructuras colectivas y se convirtió en un conjunto de productores individuales. Un grupo de estos beneficiarios de la reforma agraria vendió parte o toda la tierra recibida.

18 Los datos sobre el crecimiento de la población rural se basan en CEPAL (2019). 


\section{Cuadro 4. Aproximaciones a la evolución de la estratificación de las familias} dedicadas a la agricultura en Nicaragua, 1971-2011

\begin{tabular}{cccc} 
& 1971 & 1989 & 2011 \\
\hline $\begin{array}{c}\text { Familias sin acceso directo a la tierra cuyos miembros } \\
\text { trabajan como asalariados agrícolas }\end{array}$ & $37 \%$ & $22 \%$ & $36 \%$ \\
\hline $\begin{array}{c}\text { Familias con áreas menores a 10 mz. (minifundistas) } \\
\text { Familias con áreas mayores a 10 mz. } \\
\text { (resto de productores) }\end{array}$ & $27 \%$ & $30 \%$ & $38 \%$ \\
\hline $\begin{array}{c}\text { Beneficiarios de la reforma agraria } \\
\text { TOTAL }\end{array}$ & $0 \%$ & $24 \%$ & $26 \%$ \\
\hline Número de familias agrícolas (miles) & $100 \%$ & $100 \%$ & $100 \%$ \\
\hline
\end{tabular}

Nota: Las familias sin tierra se definieron mediante la combinación de información de los censos agropecuarios de 1971 (Oficina Ejecutiva de los Censos, 1972) y de 2011 (INIDE, 2011) y de los censos de población de 1971 y 2005 (INIDE, 1971 y 2005), e INIDE y MAGFOR (2011). La información sobre 1989 fue tomada de Baumeister (1998, p. 189). Las categorías de menos de $10 \mathrm{mz}$. se consideran un proxy de campesinos pobres o minifundistas y las de más de $10 \mathrm{mz}$. hacen referencia a un amplio sector de productores individuales que se diferencian de los minifundistas y de los sujetos de reforma agraria. Por último, se encuentra el estrato beneficiario de la reforma agraria, específico de la década del ochenta, que formó parte de las cooperativas agrícolas de producción.

Fuentes: datos sobre 1971 y 1989 tomados de Baumeister (1998, pp. 187-189); datos sobre 2011 estimados a partir de información de INIDE (2005) e INIDE (2011); datos sobre población económicamente activa (PEA) rural tomados de CEPAL (2019).

\section{Causas del creciente peso de las familias sin tierra y minifundistas}

El peso creciente de las familias sin tierra y de los minifundistas está asociado a varios factores, que se presentan a continuación:

a. Ya tenían un peso importante antes de la reforma agraria, que fue acompañado del fuerte crecimiento demográfico del país en el período 1960-2000. Recién en los últimos diez años este ha comenzado a descender como consecuencia de la reducción general de las tasas de natalidad y de mortalidad.

b. A su vez, Nicaragua es un país donde la población rural sigue creciendo en términos absolutos (véase el Cuadro 5), a diferencia de la mayor parte de América Latina. Ello aumenta la población rural en edad activa; consecuentemente, aumenta el peso de los ocupados en parcelas familiares cada vez más divididas o en empleos asalariados temporales, lo que incrementa el subempleo rural. Si bien disminuyó la proporción de pobres rurales, en términos absolutos la magnitud se mantiene casi constante (véase el Cuadro 6). 
c. A las razones anteriores se suma un patrón productivo, en todos los estratos, fuertemente extensivo, con un bajo valor bruto de la producción agropecuaria por unidad de superficie trabajada. Es el más bajo de Centroamérica, con diferencias muy marcadas con Costa Rica y el resto de la región.

d. Dentro del estrato con menos acceso a la tierra, destacan las pequeñas parcelas en manos de mujeres. Según el censo de 2011, el 62\% de las fincas pertenecientes a mujeres se ubicaba en el grupo de menos de 5 mz., mientras que los titulares varones en la misma condición representaban un $42 \%$ del total de productores varones. Se debe tener en cuenta que, entre los parámetros productivos del país, este estrato es considerado, en general, de muy baja capacidad de acumulación.

e. Las familias pobres rurales en 1993 constituían el $76 \%$ según datos del Instituto Nicaragüense de Estadística y Censos (INEC, 2003) y, en 2017, el 56\%, según la Fundación Internacional para el Desafío Económico Global (FIDEG); en 1993, esta proporción alcanzó a 1.553 .000 de personas, y en 2017 equivale a 1.503 .000 de personas, o sea, no ha tenido variaciones en términos absolutos, debido a que el crecimiento de la población rural fue superior al ritmo de reducción de la pobreza. Un estudio del Banco Mundial de 2017 llega a conclusiones similares (Banco Mundial, 2017, p. 22).

\section{Cuadro 5. Evolución de la población rural y proporción sobre la población total en Nicaragua, 1970-2018}

\begin{tabular}{ccc}
\hline Años & $\begin{array}{c}\text { Nicaragua, } \\
\text { población rural (en miles] }\end{array}$ & $\begin{array}{c}\text { [1970-2018] } \\
\text { porcentaje de población }\end{array}$ \\
\hline $\mathbf{1 9 7 0}$ & 1270 & $52,8 \%$ \\
\hline $\mathbf{1 9 9 0}$ & 1945 & $46,6 \%$ \\
\hline $\mathbf{2 0 0 0}$ & 2253 & $44,4 \%$ \\
\hline $\mathbf{2 0 1 0}$ & 2472 & $42,4 \%$ \\
\hline $\mathbf{2 0 1 8}$ & 2607 & $40,3 \%$ \\
\hline
\end{tabular}

Fuente: FAO (s. f. a) y cálculos propios.

Cuadro 6. Proporción de población rural pobre en Nicaragua, 1993-2017

\begin{tabular}{cc} 
Años & Porcentaje de pobres rurales [1993-2017) \\
\hline 1993 & $76 \%$ \\
\hline 1998 & $69 \%$ \\
\hline
\end{tabular}




\begin{tabular}{ll}
\hline 2001 & $68 \%$ \\
\hline 2010 & $63 \%$ \\
\hline 2017 & $56 \%$ \\
\hline
\end{tabular}

Fuente: De 1993 a 2001, datos tomados del INEC (2003); para 2010-2017, datos de la FIDEG, citada por Baumeister y Marti i Puig [2018, p. 307).

\section{Creación de las condiciones estructurales para la migración rural hacia Costa Rica}

En el momento anterior a las fuertes migraciones hacia Costa Rica, en 1978, Nicaragua tenía cerca de 424.000 ha de cultivos comerciales que demandaban un volumen importante de mano de obra temporal interna; existía una relación de 1 ha de cultivo comercial por cada miembro de la PEA rural. En esa misma época, en Costa Rica había 2,5 personas de la PEA rural por cada hectárea de cultivo comercial, relación muy superior a la de Nicaragua (véase el Cuadro 7).

Hacia 1990, cuando se inició el proceso masivo de migraciones hacia las actividades agrícolas costarricenses, se observa un panorama muy diferente. En Nicaragua, con la desaparición de la siembra del algodón, el área de cultivos comerciales era muy inferior a la de 1978, pero la PEA rural había crecido de manera significativa, producto del importante aumento de la población rural en las décadas previas. En consecuencia, había una relación de 2,2 miembros de la PEA rural por cada hectárea de cultivos comerciales. Ello colocaba a cerca de la mitad de este estrato en condiciones de mayor subempleo también en el momento de máxima demanda, y una parte de estos - con diferencias según grupo de edad, género, pertenencia a familias con tierra, región del país y nivel de capital social migratorio- ${ }^{19}$ podría emigrar hacia Costa Rica, en modalidad permanente o temporal. ${ }^{20}$

En el Cuadro 8 puede verse que esa disponibilidad de la PEA rural nicaragüense se mantiene hasta el presente. Por el contrario, la disponibilidad de PEA rural por hectárea de cultivos permanentes en Costa Rica, que se inicia con 2,5 personas por hectárea, se reduce en el resto de los momentos seleccionados. Son dos las razones: por un lado, crecen permanentemente las áreas de cultivos comerciales, tanto de los antiguos —el banano y la caña de azúcar - como de los más recientes — la palma africana y la piña—; por

19 Experiencia y contactos para cruzar la frontera tanto en forma legal como ilegal, trabajo y alojamiento en los lugares de destino, obtenidos por la información de parientes, conocidos o compañeros de trabajo.

20 Los condicionantes estructurales pesan en esos procesos, pero el volumen de capital social migratorio controlado es decisivo en la concreción del desplazamiento. 
otro lado, la PEA rural crece a menor ritmo y finalmente disminuye, debido a dos procesos paralelos, fuertes emigraciones del campo a la ciudad y menor crecimiento poblacional en el país. ${ }^{21}$

La atracción de la mano de obra agrícola se produce, también, porque los salarios pagados en Costa Rica son superiores a los de Nicaragua. ${ }^{22}$ En la actualidad, puede estimarse que el salario diario de un trabajador nicaragüense en Costa Rica, en promedio, oscila entre USD 10 y USD 13 por día, mientras que en Nicaragua es de entre USD 5 y USD 7 por día. ${ }^{23}$

\section{Cuadro 7. Evolución de las superficies de cultivos comerciales y de la PEA rural en Nicaragua y Costa Rica, 1978-2018}

\begin{tabular}{ccccc}
\hline Cultivos y PEA rural & 1978-1980* & 1990 & 2000 & 2018 \\
\hline & Nicaragua & & & \\
\hline Cultivos comerciales [ha+] & 424.000 & 269.000 & 395.000 & 475.000 \\
\hline PEA rural & 479.000 & 598.000 & 755.000 & 1.145 .000 \\
\hline PEA rural/ha & 1,1 & 2,2 & 1,9 & 2,4 \\
\hline Cultivos comerciales [ha++] & 179.000 & 223.000 & 292.000 & 353.000 \\
\hline PEA rural & 455.000 & 539.000 & 603.000 & 444.000 \\
\hline PEA rural/ha & 2,5 & 2,4 & 2,1 & 1,3 \\
\hline
\end{tabular}

* Para Nicaragua, datos de 1978; para Costa Rica, datos de 1980.

Cultivos comerciales: ${ }^{+}$palma africana, algodón, caña de azúcar, banano, café, frijol y piña. ${ }^{++}$palma, caña de azúcar, banano, café, melón, naranja, piña y yuca.

Fuentes: para cultivos, FAO (s. f. a); para la PEA rural, CELADE (2019).

\section{Otros factores actuantes en Nicaragua}

Primero, se encuentra el continuo crecimiento de la población rural. Esta población y la PEA rural siguen aumentando, con lo cual necesitan más oportunidades de empleo e ingresos, a diferencia de la mayor parte de los países de América Latina, donde hace tiempo no crecen estos sectores. Las estima-

21 La expansión urbana se generalizó luego de la Segunda Guerra Mundial, con lo cual se iniciaron fuertes procesos de migraciones desde el campo, pues las ciudades ofrecían, en términos relativos, mejores ingresos monetarios y mayor acceso a la educación y la salud.

22 En 1993, el salario por día de trabajo de un peón agrícola en Costa Rica se estimaba en USD 6,01, mientras que en Nicaragua era equivalente a USD 1,66 (CEPAL, 1998, p. 258).

23 Según conversatorios con trabajadores nicaragüenses con experiencia migratoria (enero de 2020) e indagaciones en Costa Rica. 
ciones de CELADE consideran que la PEA rural en Nicaragua crecerá en términos absolutos, por lo menos, hasta 2050. ${ }^{24}$

Segundo, existe un alto subempleo en el área rural. El empleo precario en las zonas rurales se manifiesta en que, durante 2017 , un $49,2 \%$ de los ocupados, en sus distintas inserciones laborales, trabajaba menos de 40 horas semanales. Ello no se producía por decisión propia, sino porque su trabajo como asalariado temporal era solo durante algunos días u horas a la semana, o porque el trabajo en la parcela familiar no requería más que unas pocas horas al día - ya sea para el jefe o jefa del hogar o para miembros de la familia- y no tenían un trabajo remunerado fuera del hogar (FIDEG, 2017).

Tercero, la emigración hacia Costa Rica y otros destinos ha aumentado. En 2005, viajaron en condiciones legales a Costa Rica 239.200 personas, lo cual arrojaba una relación de 4,7 personas por cada 100 habitantes, tanto para viajes cortos como para estancias más prolongadas. En 2017, viajaron legalmente a Costa Rica 436.000 personas: con una relación de 6,8 personas por cada 100 nicaragüenses; ello significa que el número de viajeros con papeles medido en relación con la población total del país se incrementó en ese período en $44,6 \%$. Es pertinente relacionar estos datos con las condiciones de subempleo en las zonas rurales y con la reducción de las áreas de granos básicos por familia, además de las condiciones generales de pobreza y de bajos salarios predominantes. ${ }^{25}$ Todos estos indicadores muestran la fuerte vulnerabilidad de amplios sectores poblacionales rurales de Nicaragua, con una fuerte contradicción: aunque muchos pueden tener algún acceso a la tierra en pequeña escala, no logran maximizar la producción de autoconsumo en esas parcelas. ${ }^{26}$

24 En la revisión 2019 del Centro Latinoamericano y Caribeño de Demografía (CELADE), se estima una PEA rural de 1.162 .000 personas para 2019 y de 1.516 .000 personas para 2050 (CELADE, 2019).

25 En Nicaragua pueden estimarse salarios agrícolas de entre USD 4 y USD 5 por día, mientras que en Costa Rica pueden oscilar entre USD 10 y USD 13 por día para trabajadores migrantes. El área cultivada de maíz por familia rural en Nicaragua era de 0,7 ha en 2011; para 2018, fue de 0,5 ha, asumiendo un tamaño medio de 5 personas por familia (FAO, s. f. a, y cálculos propios).

26 Existen varios factores asociados. En primer lugar, está el fuerte predominio de una cultura que privilegia los ingresos monetarios ganados en la venta de productos o en el trabajo asalariado, y menosprecia, en parte, la producción de autoconsumo. En segundo lugar, predomina una alimentación muy centrada en los granos básicos, como el maíz y el frijol, producidos para el autoconsumo y la venta; no sucede lo mismo con otros productos - hortalizas, frutas y animales menores- que, en pequeña escala, pueden contribuir a mejorar la dieta a partir del autoconsumo. En tercer lugar, el bajo dominio del riego, aun en sus formas más simples, impide la producción de patio durante la larga estación seca y la obtención en muy pequeña escala de más hortalizas y frutas para el autoconsumo. 


\section{Estratos de productores agropecuarios en Costa Rica y Nicaragua}

En Costa Rica, los pequeños y medianos productores siguen siendo importantes actores en rubros como la ganadería vacuna y el cultivo de café y hortalizas para el mercado interno. Sin embargo, su presencia en la proporción del valor bruto de la producción total está en declive, mientras la relevancia de empresas de mayor tamaño es significativa. Estos grandes productores desarrollan cultivos como la piña, la palma africana y los bananos, que han crecido en las últimas décadas.

En Nicaragua, los pequeños y medianos agricultores tienen una preponderancia productiva importante en ganadería vacuna, café y granos básicos. Los grandes se concentran en el cultivo de caña de azúcar, con una parte importante de la producción generada por los propios ingenios azucareros o grandes colonos de esos ingenios. También participan en la siembra de maní y de palma africana, y en plantaciones nuevas, como la variedad de café denominada robusta y algunas plantaciones de cacao, estos dos últimos en zonas de la costa atlántica y el río San Juan. Las estructuras empresariales más fuertes se ubican en el procesamiento agroindustrial - beneficios de café, mataderos de ganado vacuno, plantas lecheras, ingenios azucareros, procesamiento de tabaco de tipo habano- $-\mathrm{y}$ en el control de las exportaciones de los principales rubros.

Pero en la comparación entre ambos países cabe recordar el Cuadro 3, en el que se observa que las exportaciones agrarias de Costa Rica son más del doble que las de Nicaragua, diferencias muy marcadas que tienen que ver con productividades por unidad de superficie mucho más elevadas en Costa Rica, por el tipo de cultivos que produce y por la mayor productividad de la ganadería vacuna,${ }^{27}$ lo cual tiene incidencia en los niveles de productividad por persona trabajando y en los ingresos del trabajo.

\section{Tendencias de acceso a la tierra y concentración de la tierra y la producción}

En Costa Rica, el acceso a la tierra para nuevos agricultores es limitado; la mayor parte labora como asalariado permanente o temporal. La producción de granos básicos se ha restringido fuertemente en las últimas décadas, por lo que se importa cerca del $85 \%$ de los cereales consumidos (FAO, s. f. a, y cálculos propios). La concentración de la tierra en fincas no se ha ampliado, pues el estrato superior a las 200 ha sigue teniendo el mismo peso que en la década del setenta. Sin embargo, se observa un marcado incremento de la concentración de la producción en grandes unidades, por el predominio que presentan en rubros crecientemente importantes como la palma africana, el banano, la piña y la industria avícola.

27 Hacia 2018 puede estimarse que el valor agregado agropecuario por hectárea era de 400 dólares corrientes en Nicaragua, y en Costa Rica era cercano a 1500 dólares por hectárea (cálculos propios basados en FAO, s. f. a). 
En el caso de Nicaragua, un primer elemento que se debe considerar a diferencia de Costa Rica es que la población y la PEA rurales siguen creciendo y, por lo tanto, lo hacen también las necesidades de los hogares agrícolas. Se observa que el crecimiento de estos sectores de la población es mayor que el aumento de las posibilidades de acceder a nuevas tierras, ya sea por compra o por ampliación de la frontera agrícola, con lo cual se incrementan las familias rurales sin acceso directo a este recurso. En muchos casos, dicho acceso se da en parcelas de muy pequeña extensión, debido al fraccionamiento de la tierra por los procesos de herencia dentro de las familias. La concentración de este recurso se ha ampliado en los años 2000, luego de haberse reducido durante la reforma agraria de los ochenta. Hay procesos de compraventa en rubros como la ganadería vacuna y el cultivo de palma africana y caña de azúcar.

En Nicaragua, las tendencias en la estructura agraria permiten dos lecturas, según se observe exclusivamente la distribución de la tierra o se incluya la estructura de clases más amplia, que contiene a los hogares rurales sin acceso a la tierra que generan una parte sustantiva de los asalariados permanentes o temporales. Si se observa la distribución de la tierra entre distintos tipos de unidades de producción y sus modificaciones por la reforma agraria y procesos posteriores, se constata una mayor relevancia de estratos de medianos productores y una reducción del peso del estrato más grande. Ambos procesos fueron generados inicialmente por la reforma agraria, por la propia iniciativa de las unidades colectivas - cooperativas - y por la reapertura de la frontera agrícola luego de 1990, al finalizar del conflicto armado interno. La segunda interpretación posible, también válida, integra a todas las clases agrarias incluyendo a los asalariados sin tierras. Esta manera de entender la realidad agraria hace énfasis en el "regreso" a la estructura de clases constituida históricamente, que articula fuertemente estratos proveedores de mano de obra permanente y estacional con sectores demandantes de esa fuerza de trabajo (ver Cuadro 4). A diferencia del modelo clásico agroexportador, anterior a 1980, donde el proceso de demanda se hacía exclusivamente dentro de Nicaragua, ahora esta extiende también su geografía más allá de las fronteras.

\section{Condiciones de la fuerza de trabajo agrícola nicaragüense en Costa Rica}

Cabe distinguir dos grandes segmentos poblacionales de nicaragüenses en Costa Rica: los que viven la mayor parte del tiempo dentro de Costa Rica y aquellos que ingresan a dicho país y retornan a Nicaragua con mayor frecuencia. A continuación, se presenta la situación de quienes viven de manera más permanente en Costa Rica.

En el Cuadro 8 se muestra la situación del segmento más legalizado de los nicaragüenses que viven permanentemente en Costa Rica, entrevistados para la Encuesta Continua de Empleo (ECE) del Instituto Nacional de Estadística y Censos (INEC). 
Se observa que un $50 \%$ de este segmento - hombres y mujeres- trabaja en condiciones de informalidad, lo que se deduce por el hecho de que los empresarios no realizan aportes a la seguridad social. Por lo tanto, estas personas están impedidas de acceder a los servicios de la Caja Costarricense de Seguro Social (CCSS), salvo en situaciones de emergencia, y no podrán jubilarse en su vejez.

\section{Cuadro 8. Condiciones de los trabajadores agrícolas nacidos en Nicaragua que trabajan permanentemente en Costa Rica, 2019}

\begin{tabular}{ccc} 
& Porcentaje & Fuentes \\
\hline Condición de informalidad & $50,3 \%$ & ECE, IV trimestre de 2019 \\
\hline Ingresos menores al salario mínimo & $32,1 \%$ & ECE, II trimestre de 2019 \\
\hline Condición de pobreza multidimensional & $54,0 \%$ & ENAHO, 2019 \\
\hline $\begin{array}{c}\text { Ingresos menores al salario mínimo con más } \\
\text { de } \mathbf{4 0} \text { horas semanales de trabajo }\end{array}$ & $25,5 \%$ & ECE, II trimestre de 2019 \\
\hline
\end{tabular}

Fuentes: Además de las señaladas en el cuadro, cálculos propios.

Cabe señalar que, sin considerar la nacionalidad del trabajador, sobre los ingresos monetarios necesarios para cubrir el costo de vida de los trabajadores agrícolas en Costa Rica concluye que los salarios percibidos en 2016 en el sector bananero y piñero cubrían el $66 \%$ del salario digno; el salario agrícola mínimo llegaba al 50\% de ese monto de referencia. ${ }^{28}$

Es significativo advertir que la proporción de trabajadores agrícolas costarricenses en situación de pobreza multidimensional — que considera principalmente los factores tipo de vivienda, salud y educación- es de 31,5\%. Ello contrasta con la situación de los trabajadores nicaragüenses indicada en el Cuadro 8. Los otros factores, relacionados con la informalidad y con los ingresos menores al salario mínimo, son problemas que también padecen los trabajadores agrícolas costarricenses.

28 Este cálculo se realizó sobre la base de una familia de cuatro personas: dos menores y 1,56 trabajadores activos que generan ingresos. Se incluyeron gastos de alimentación, alquiler de vivienda, vestido y educación a partir de criterios relativamente modestos (Voorend, Anker y Anker, 2017). Un comentario generalizado en los conversatorios fue que, en la actualidad, no es conveniente para un trabajador nicaragüense vivir con su familia en Costa Rica, debido a los elevados costos de vida; consideran que lo más adecuado es el traslado individual de un hombre o de una mujer, pagar lo mínimo de renta por un cuarto y ahorrar lo máximo para enviar a Nicaragua. Cuando se puede ahorrar, es para mejorar los activos en Nicaragua, nunca en Costa Rica, por los elevados precios de terrenos y casas. 


\section{Estimación del empleo agrícola costarricense incluyendo el componente de migración temporal}

Las estimaciones oficiales de la ECE (INEC, IV trimestre de 2019) arrojan un total de 261.700 ocupados en la agricultura, que incluyen 226.000 costarricenses, 31.000 nicaragüenses y el resto de otras nacionalidades, principalmente indígenas panameños. La estimación que hemos realizado con datos del INEC, del Banco Central de Costa Rica (BCCR), del Instituto del Café de Costa Rica (ICAFE) y del Ministerio de Agricultura y Ganadería (MAG) eleva el número de ocupados a cerca de 358.000 personas en $2019 .{ }^{29}$ De este total, 249.300 son costarricenses, según la suma de los estimados por la ECE y un adicional de otros trabajadores para el corte del café. El resto son básicamente nicaragüenses en sus distintas condiciones, como se aclara a continuación.

En el período 2006-2007, según los cálculos, los nicaragüenses que trabajaban en el agro costarricense eran alrededor de 71.000 - un $24 \%$ de la mano de obra agrícola del país receptor- De estos, 23.000 vivían permanentemente en Costa Rica y 48.000 se desplazaban temporalmente (Baumeister, Fernández y Acuña, 2008, p. 91). A fines de 2019, puede estimarse que los nicaragüenses sumaban, de manera aproximada, 107.000 - un $30 \%$ de la mano de obra agrícola de Costa Rica-. Alrededor de 60.000 están en Costa Rica permanentemente: unos 31.000 con documentos en regla y 29.000 con documentación irregular, y poco más de 46.000 se desplazaron temporalmente desde Nicaragua (estimaciones propias basadas en BCCR, INEC, ICAFE y MAG).

Para analizar estos cálculos, es necesario tener en cuenta dos hechos principales:

a. En 2000, la cantidad de población nicaragüense que vivía en Costa Rica era de 226.000 (CELADE, s. f.); en 2011, de acuerdo con la estimación del Centro Centroamericano de Población (CCP) de la Universidad de Costa Rica (UCR), esta cifra era de 365.000, según la rectificación hecha por el CCP a los datos del Censo de Población de 2011 (CCP, 2013).

b. La mano de obra demandada por el banano y la piña se ha incrementado por aumento de las áreas trabajadas. Además, estos cultivos re-

29 Se utilizan datos de la ECE del INEC, de la Matriz de Empleo del BCCR, de las estimaciones sobre la mano de obra para el corte de café del ICAFE, datos recabados mediante una entrevista a Marco Araya Molina, del Área de Asuntos Económicos (entrevista y comunicación por correo, 28 de febrero de 2020); de las estimaciones del MAG para el corte manual de caña de azúcar recogidas de Barquero (2019) y del Censo Agropecuario de 2014, para estimar más adecuadamente el número de productores dentro de los ocupados en el agro. Una proyección econométrica, realizada por la OIT (2021), arroja para 2019 un estimado de 300.000 trabajadores en la agricultura de Costa Rica. 
quieren más mano de obra todo el año: siembras, mantenimiento de canales de riego, aplicación de productos químicos, cosecha manual y preparación de las frutas para la exportación (lavado y embalado en cajas para la exportación). ${ }^{30}$ Por otro lado, el requerimiento de mano de obra en el corte de café ha disminuido por la reducción del volumen de producción, sin embargo, sigue siendo el principal demandante de mano de obra en la agricultura. Este rubro ha tenido siempre un importante segmento de trabajadores temporales que viven básicamente en Nicaragua. ${ }^{31}$

\section{COVID-19 y el trabajo agrícola de los nicaragüenses en Costa Rica en 2020-2021}

A partir de 1990 se aceleró la migración nicaragüense a Costa Rica, en dos modalidades principales: la migración permanente, que busca insertarse lo más legalmente posible en Costa Rica, y un flujo muy importante conformado por personas que viajan por vías relativamente formales y por un segmento elevado que viaja por períodos estacionales sin papeles, tanto al entrar como a la salida de Costa Rica. ${ }^{32}$

En relación a la agricultura costarricense, se destacan ambas modalidades de migración hacia Costa Rica, con un incremento en los últimos diez años de una población flotante entre ambos países, pero que tiende a permanecer por períodos más prolongados en Costa Rica en condiciones no legales, debido al auge de cultivos como la piña y la palma aceitera, que requieren más mano de obra durante los doce meses, a diferencia del café, que tiene un muy fuerte componente estacional durante el período de la cosecha.

Existe consenso en que los trabajadores nicaragüenses que viven de manera más permanente en Costa Rica — documentados, indocumentados y migrantes temporales - son un sector fundamental en las tareas agrícolas

30 Esto diferencia a estos dos cultivos del café, que tienen una marcada demanda de mano de obra en los tres meses de cosecha que van habitualmente de noviembre a enero del año siguiente.

31 En 2006, el cultivo de piña ocupaba 23.000 ha; en 2018, 45.000 ha. Las plantaciones de banano pasaron, en igual período, de 42.800 ha a 48.000 ha. Por su parte, los campos de café disminuyeron de 99.000 ha en 2006 a 84.000 ha en 2018 (FAO, s. f. a).

32 Hay que tener en cuenta que buena parte del borde fronterizo entre ambos países está formado por el río San Juan, que tiene una extensión aproximada de 200 kilómetros y es utilizado con medio de comunicación interna de los países y con mucha facilidad para cruzar a la otra orilla y dejar pasajeros. De igual modo, las fronteras terrestres son también bastante porosas, en particular por el hecho de que los habitantes más cercanos a ambas fronteras tienen fuertes lazos familiares y de intercambio comercial, lo cual facilita el desplazamiento de los migrantes no documentados nicaragüenses. A lo cual se agrega la ambigua política costarricense hacia la migración no documentada, que oscila entre períodos de mayor control con otros mucho más laxos. 
costarricenses..$^{33}$ Desde los años 2000 y con mayor relevancia desde fines de la segunda década del siglo actual, se fue incrementando la población nicaragüense que vive de manera permanente en Costa Rica. ${ }^{34}$ Entre 2006 y 2018, la población nacida en Nicaragua que vive en Costa Rica, estimada por las encuestas nacionales de Costa Rica, se incrementó en cerca de 45,6\% (INEC, 2006 y 2019), con una tasa media de crecimiento superior, tanto en relación a las tasas de Costa Rica como a las de Nicaragua, indicios claros de la presión migratoria hacia los dos países.

Cuando en marzo de 2020 se masificó la epidemia de COVID-2019, se cerraron todas las fronteras, lo que dificultó la entrada de nicaragüenses a Costa Rica, y un sector regresó a Nicaragua. ${ }^{35}$ En el mes de marzo, prácticamente todas las cosechas principales (café y caña de azúcar) se habían recolectado, por lo cual el ciclo agrícola 2019-2020 no se afectó. Pero creció fuertemente la preocupación por el nuevo ciclo agrícola, 2020-2021 (que va de manera convencional desde mayo a abril), con las fronteras cerradas y el temor de que los nicaragüenses fueran un factor de trasmisión de COVID-19 (Lang Oreamuno, 2020). ${ }^{36}$

En el marco de una preocupación por obtener mano de obra temporal, el Estado y las cámaras empresariales vinculadas al agro comenzaron a formular iniciativas para ver cómo enfrentar el nuevo ciclo agrícola (2020-2021), particularmente las cosechas de los principales cultivos que se inician hacia el mes de octubre y llegan hasta marzo del año siguiente.

Un balance preliminar sobre los vínculos del COVID-19 y las labores agrícolas, incluyendo el rol de los migrantes, indica, más allá del cierre de las fronteras y otras complicaciones propias de la pandemia, que el ciclo agrícola, en especial en rubros como el café, con una fuerte demanda temporal de mano de obra, particularmente nicaragüense, ha transcurrido con bastante normalidad y se espera que cuando finalice la cosecha 2020-2021 el volumen recolectado sea muy cercano al esperado y similar al de los años anteriores,

33 Ver Herrera (2019).

34 El incremento de la población de origen nicaragüenses en Costa Rica se fue acumulando desde comienzos de los años 2000; a partir de 2018, debido a la crisis política interna en Nicaragua, se amplió el número de migrantes nicaragüenses hacia Costa Rica.

35 Hay estimaciones que muestran que la población nicaragüense que reside permanentemente en Costa Rica y es captada por la Encuesta Nacional de Hogares (ENAHO) se redujo en 9,5\% entre 2019 y 2020 (INEC, 2019 y 2020). El regreso se debió a dos razones básicas: el cierre de empresas vinculadas a las actividades turísticas y el comercio, fuertemente impactadas por la pandemia, y la presión de las autoridades costarricense en los primeros meses de la enfermedad, debido a la creencia de que los nicaragüenses eran importantes portadores del virus.

36 "Es una situación compleja para el sector agropecuario porque, por un lado, dependemos de la mano de obra extranjera, pero, al mismo tiempo, les cerramos las puertas. Parte de estos trabajadores vive en otros países y viene a trabajar a las fincas tan solo por unas horas o días, se le paga por trabajo realizado" (Oscar Arias Moreira, vocero de la Cámara Nacional de Agricultura y Agroindustria de Costa Rica, citado en Flores, 2019). 
aunque un poco menor debido al irregular régimen de lluvias durante el año agrícola (SEPSA, 2020).

Sobre cómo se enfrentó el reclutamiento de mano de obra temporal para el corte de café, cabe distinguir las siguientes iniciativas:

a. Ministerios de Agricultura y del Trabajo de Costa Rica (Ministerio de Agricultura y Ganadería, 2020). Desde comienzos del ciclo agrícola 2020, el ministro de Agricultura, Renato Alvarado, inició una campaña para legalizar de alguna manera la mano de obra, fundamentalmente nicaragüense, que residía en Costa Rica desde antes de la pandemia. Logró registrar un total de 13.000 trabajadores, cifra inferior a las expectativas de reunir un número mayor de registrados como trabajadores migrantes dispuestos a trabajar en la agricultura, teniendo en cuenta que solo el pico de mano de obra del café ronda en más de 70.000 trabajadores en el mes de enero. ${ }^{37}$

b. Acuerdo binacional Costa Rica-Nicaragua para permitir la entrada formal de trabajadores nicaragüenses, incluyendo acciones del Ministerio de Salud de Costa Rica para el cumplimiento de las normas sanitarias. ${ }^{38} \mathrm{El}$ acuerdo se estableció hacia noviembre de 2020, como parte de las medidas para ampliar el número de trabajadores agrícolas temporales, ya iniciada la recolección del café en Costa Rica, principal demandante de mano de obra temporal. ${ }^{39}$ Se enfatizaron las medidas sanitarias en el traslado, que debió hacerse mediante autobuses expresamente fletados para este propósito y pagados por los empleadores. La información disponible, reflejada en el Cuadro 10, muestra que en el ciclo 2020-2021 se trasladaron cerca de 5.000 trabajadores, un número muy por debajo de la meta de 20.000 .

c. Otros mecanismos en el reclutamiento de mano de obra en 20202021. Los mecanismos de atraer trabajadores para las tareas de recolección de las cosechas, particularmente para el café, fueron varios.

37 "El decreto permite regular la mano de obra extranjera pero con arraigo. Este decreto cobija a personas dedicadas a trabajos agrícolas, que ingresaron al país entre enero de 2016 y enero de 2020. El ministro de Agricultura y Ganadería, Renato Alvarado, indicó que este decreto permite facilitar trabajadores que ingresaron antes del 15 de enero al país y evitar un serio impacto en la producción nacional a raíz de la pandemia por COVID-19. Esta mano de obra es necesaria, porque a pesar de los esfuerzos realizados para que los costarricenses se apunten en labores agrícolas, no es suficiente" (Delgado, 2020). De acuerdo a la información del Ministerio de Agricultura y Ganadería, se lograron anotar 13.000 trabajadores bajo esta condición de personas con arraigo (Jiménez Flores, 2020).

38 Acuerdo binacional que buscaba el traslado seguro de 20.000 trabajadores nicaragüenses a tareas temporales en Costa Rica en 2020 (EFE, 2020).

39 Cultivos como piña, la palma aceitera y los bananos tienen una demanda de mano de obra relativamente más estable a lo largo del año agrícola; sin embargo, pueden recurrir a contratos de algunos meses, renovables, para disminuir costos en las cargas sociales del empleador. 
En primer lugar, las iniciativas señaladas en los puntos a) y b) no podían resolver la parte de trabajadores extranjeros necesarios para el período de mayor demanda, en los meses de diciembre y enero, por tanto, mecanismos informales lograron incorporar mano de obra nicaragüense que vivía en Costa Rica en condiciones legales precarias o migrantes transfronterizos que no entraron por los puestos fronterizos, que estaban cerrados. ${ }^{40}$

En los Cuadros 9 y 10 se presenta una aproximación a lo sucedido con el período de corte del café, comparando el cuarto trimestre de 2019 con su equivalente de 2020, que son los cuatrimestres de fuerte demanda para la recolección del café. Se toma la información que arroja la ECE de Costa Rica para los asalariados en ocupaciones elementales, un proxy aceptable para los recolectores del café. Los costarricenses representan alrededor de un $40 \%$ de los recolectores en ambos períodos, lo cual coincide con las estimaciones habituales del ICAFE. ${ }^{41}$

Hay un segmento de trabajadores de origen nicaragüense y panameños captados por la ECE, ${ }^{42}$ que integran el conjunto más legalizado y que reside desde hace bastante tiempo en el país. ${ }^{43}$ Es probable que el número real de panameños se acerque a los 2.000 trabajadores en los dos momentos analizados. Pero el gran complemento del número de trabajadores lo proporcionan los "otros" nicaragüenses, tanto los que viven de manera precaria en Costa Rica (registrados por el MAG) como los que cruzan sin papeles desde Nicaragua y los que entraron por el acuerdo binacional de noviembre de 2020). En los dos momentos (último trimestre de 2019 y último trimestre de 2020, estos segmentos suman más del $50 \%$ de los cortadores. ${ }^{44}$ Cabe aclarar que una parte, probablemente menor pero difícil de estimar, de los registrados por el MAG de Costa Rica y por el acuerdo binacional se desplazó a actividades

40 En el año 2020 el flujo de viajeros nicaragüenses registrados que entraron a Costa Rica fue un $85 \%$ inferior al observado en 2019. Estimación propia basada en las estadísticas de la Dirección de Migración y Extranjería de Costa Rica (2020).

41 Entrevista telefónica con la gerenta de ICAFE, Xinia Chaves, 2 de febrero de 2021.

42 Esta encuesta no tiene capacidad de captar a los migrantes temporales porque el marco muestral está basado en el Censo de Población de 2011, que tuvo dificultades para captar el número de nicaragüenses que vivía de manera permanente en Costa Rica; mientras que el censo registró un poco menos de 288.000 personas, la revisión posterior del CCP de la UCR arrojó cerca de 365.000 personas (CCP, 2013).

43 Y que puede ser captado por el muestreo de la ECE.

44 La estimación de cerca de 74.000 trabajadores realizada por el ICAFE es aceptable: según los datos disponibles en el mes de enero se recolecta cerca del 30\% de la cosecha; para 20212022 eso supone 1,7 millones quintales de café oro (un quintal oro equivale a 46 kilos) que equivalen a 34 millones de cajuelas de café en fruta, los cuales en el momento pico de la cosecha equivalen a 10,2 millones de cajuelas; si se trabajan 25 días por mes eso arroja un promedio de entre 5 y 6 cajuelas por cortador por día, que es el promedio del grueso de los cortadores, según la opinión de los técnicos del ICAFE consultados. 
de cosecha distintas del café; esto significa que los nicaragüenses no registrados puedan ser una proporción mayor que la reflejada en los Cuadros 9 y 10.

\section{Cuadro 9. Costa Rica, asalariados en ocupaciones elementales en café, cuartos trimestres de 2019 y $2020^{45}$}

\begin{tabular}{ccccc}
\hline $\begin{array}{c}\text { Segmentos de asalariados en ocupaciones } \\
\text { elementales en el café }\end{array}$ & IV 2019 & $\%$ & IV 2020 & $\%$ \\
\hline Costarricenses 1/ & 32.165 & 39,2 & 32.087 & 43,4 \\
\hline Nicaragüenses captados por la ECE 2/ & 3.843 & 4,7 & 3.050 & 4,1 \\
\hline Panameños 3/ & 1.025 & 1,2 & 720 & 1,0 \\
\hline “Otros" nicaragüenses 4/ & 45.000 & 54,9 & 38.000 & 51,5 \\
\hline Total de recolectores en promedio diciembre-enero /5 & 82.033 & 100 & 73,857 & 100 \\
\hline
\end{tabular}

1/, 2/ y 3/ son tabulaciones propias de la ECE. 4/ Residentes en Costa Rica no registrados y migrantes indocumentados, construido como diferencia entre 5 / y la sumatoria de $1 /, 2$ / y 3/. 5/ Todos los trabajadores según ICAFE.

Fuente: ECE cuarto trimestre 2019 e ICAFE.

Cuadro 10. Costa Rica, trabajadores nicaragüenses en el corte de café 20202021

\begin{tabular}{cccc} 
Trabajadores estimados según fuentes de datos & Referencia & Trabajadores & $\%$ \\
Encuestados por la ECE IV 2019 & $1 /$ & 3.050 & 7,4 \\
\hline Inscriptos por el MAG de Costa Rica [neto) & $2 /$ & 9.950 & 24,2 \\
\hline Traídos desde Nicaragua por el acuerdo binacional & $3 /$ & 4.875 & 11,9 \\
\hline "Otros" nicaragüenses & $4 /$ & 23.175 & 56,5 \\
\hline Total & & 41.050 & 100 \\
\hline
\end{tabular}

Fuente: 1/ Trabajadores asalariados en ocupaciones elementales, procesamiento propio. 2/ Siu Lanzas (2020), es neto porque se resta lo informado por la ECE para nicaragüenses; 3/ González (2021), de un total de 20.336. 4/ Residentes en Costa Rica no registrados y migrantes indocumentados.

45 El cultivo del café sigue siendo el principal demandante de mano de obra entre los cultivos de exportación; la piña, otro cultivo económicamente importante, demanda cerca de 35.000 trabajadores; la palma aceitera, cerca de 11.000 trabajadores; y el banano, cerca de 57.000, según estimaciones propias para años recientes, basadas en distintas fuentes costarricenses (INEC, BCCR e ICAFE). 


\section{Comentarios finales}

La articulación laboral entre distintas zonas geográficas al interior de los países es muy antigua en muchas situaciones, pero la complementariedad laboral estacional entre países es mucho más reciente. Desde el surgimiento del café en el siglo XIX, en Costa Rica y en Nicaragua los requerimientos de mano de obra temporal fueron complementados por personas provenientes de otras zonas agrarias o de los pequeños centros urbanos cercanos, lo que se profundizó con la expansión de cultivos como el algodón, particularmente en Nicaragua. Todo esto estuvo asociado a características biológicas del proceso productivo: diferencias en la demanda de mano de obra entre las tareas de mantenimiento de las plantaciones y el momento de la recolección, que requiere fuerte concentración de fuerza de trabajo para evitar que la maduración del grano provoque la pérdida de la uva que contiene el producto que luego se convertirá en granos de café. A esto hay que agregar la existencia de mano de obra disponible en momentos de mayor demanda, proveniente de fincas pequeñas u hogares sin tierras, que se insertaba en otros rubros (como los granos básicos de subsistencia) o en trabajos marginales en zonas urbanas durante el resto del año, así como la disponibilidad de personas que el resto del año no son parte de la PEA (fundamentalmente mujeres y menores de edad). La necesidad de cruzar fronteras nacionales, con o sin papeles, ha especializado más este proceso de migración debido a que los migrantes requieren contar con cierto capital migratorio: saber cómo cruzar fronteras, cómo llegar a las mejoras zonas productivas, cómo resolver los problemas de alojamiento y alimentación, y cómo evitar a las autoridades para que no los deporten. Junto a los trabajadores que migran anualmente, otro grupo busca documentación en Costa Rica para poder residir allí, e incluso poder entrar y salir con mayor facilidad.

La expansión de nuevos cultivos en Costa Rica, a partir de los años ochenta del siglo pasado, abarca actividades que requieren mano de obra temporal, difícil de reemplazar totalmente por medios mecánicos, como son los casos de frutas (melón, sandía o naranjas) o cultivos como la palma o la piña, que siguen necesitando de mano de obra para la recolección. Por otro lado, aumentó la demanda de mano de obra agrícola en los cultivos de exportación (café, banano y los nuevos cultivos). Pero esto se desarrolló con un paralelo proceso de urbanización, una fuerte reducción de la tasa de crecimiento de la población, el incremento de los niveles educativos y la expansión de otros sectores económicos, como el turismo y el comercio urbano, que demandaron parte de esta fuerza de trabajo originalmente rural. Y esto se dio en el marco de un fuerte incremento de las exportaciones agrarias, con niveles, por ejemplo, muy superiores a las nicaragüenses, hondureñas o salvadoreñas. Esto dio origen a las condiciones para ampliar la demanda de mano de obra externa para los principales cultivos y las actividades pecuarias en expansión (ganadería de leche y producción de animales de granja). 
Por parte de Nicaragua, cabe insistir en los siguientes factores: a) la persistencia de una producción agraria tradicional, que sigue sustentada en la ganadería vacuna, el café y la caña de azúcar, en el marco de una baja productividad por hectárea; b) la persistencia del crecimiento de la población rural, particularmente de la PEA rural, que seguirá creciendo por lo menos hasta 2050 ; c) la baja capacidad de la agricultura y de otras actividades productivas de absorber el crecimiento de la población en edad de trabajar, lo cual incrementa notoriamente el subempleo rural; y d) la creación de tres destinos laborales, particularmente para los más jóvenes: el sector informal urbano, las zonas de frontera agrícola (pero esto requiere algunos recursos que no están al alcance de los más pobres) y la migración, permanente o temporal, al exterior, particularmente a Costa Rica.

\section{Referencias bibliográficas}

Álvarez, M. (2017). Hay alternativas para no ser mayor consumidor plaguicidas del mundo. El Mundo [en línea], 4 de diciembre. Disponible en: <https:// www.elmundo.cr/opinion/alternativas-no-mayor-consumidor-plaguicidasdel-mundo/> [acceso 10/12/2020].

Aravena, J. y E. Carazo (2016). Condiciones de producción, impactos humanos y ambientales en el sector piña en Costa Rica. Informe para OxfamAlemania [en línea]. San José: Oxfam. Disponible en: <https://www.oxfam. de/system/files/condiciones_laborales_y_ambientales_de_la_pina_en_costa_rica_-_mayo_2016.pdf> [acceso 12/12/2020].

Banco Central de Costa Rica (BCCR) (s. f.). Cuentas nacionales. Periodo de referencia 2012. "Clasificación cruzada 2016” [en línea]. Disponible en: $<$ https://www.bccr.fi.cr/seccion-cuentas-nacionales-periodo-2012/cuentasnacionales-periodo-de-referencia-2012> [acceso 12/12/2020].

Banco Mundial (2017). Nicaragua. Paving the way to faster growth and inclusion. Systematic Country Diagnostic. s. 1.: Banco Mundial. Disponible en: $<$ http:/documents1.worldbank.org/curated/en/365991498843795990/pdf/ Nicaragua-SCD-Copyedit-final-jun-20-06272017.pdf $>$ [acceso 10/12/2020].

Barquero, M. (2019). Recolección de cosechas agrícolas requerirá 40.000 trabajadores temporales. Diario La Nación [en línea], 18 de septiembre. Disponible en: $<$ https://www.nacion.com/economia/agro/recoleccion-de-cosechasagricolas-requerira-4000/PS3LTDVDE5FIHFS7FK722UAHYU/story/> [acceso 09/01/2021]. 
Baumeister, E. (2021). Desigualdades en el acceso a la tierra y la inserción laboral de los nicaragüenses en la agricultura de Costa Rica. s. 1.: Iniciativa sobre la Desigualdad de la Tierra. Disponible en: <https://d3o3cb4w253x5q. cloudfront.net/media/documents/land_inequality_case_study_2021_3_nicaragua_costa_rica_nitlapan_trocaire.pdf $>$ [acceso 15/03/2021].

Baumeister, E. (1998). Estructura y reforma agraria en Nicaragua, 1979-1989. San José/Managua: Editorial CDR.

Baumeister, E.; E. Fernández y G. Acuña (2008). Sobre las migraciones regionales de los nicaragüenses [en línea]. Guatemala: Editorial Ciencias Sociales. Disponible en: <https://www.academia.edu/3558918/Sobre_las_migraciones_regionales_de_Nicarag\%C3\%BCenses $>$ [acceso 20/12/2020].

Baumeister, E. y Marti i Puig, S. (2018). Nicaragua: de la revolución estatista a la profundización agroexportadora. En C. Kay y L. Vergara-Camus (coord.). La cuestión agraria y los Gobiernos de izquierda en América Latina [en línea]. Buenos Aires: Clacso. Disponible en: <http://biblioteca.clacso.edu.ar/clacso/ se/20180608115610/La_cuestion_agraria.pdf $>$ [acceso 18/12/2020].

Bulmer-Thomas, V. (1987). The Political Economy of Central America since 1920. Cambridge: Cambridge University Press.

Centro Centroamericano de Población (CCP) (2013). Evaluación demográfica del Censo Nacional de Población de Costa Rica y otras fuentes de información. San José: CCP. Disponible en: <https://ccp.ucr.ac.cr/observa/CRnacional/pdf/Evaluacion\%20censal\%20FINAL\%20marzo\%202013.pdf> [acceso 06/12/2020].

Centro Latinoamericano y Caribeño de Demografía (CELADE) (2019). Estimaciones y proyecciones. Santiago de Chile: CEPAL. Disponible en: $<$ https:// www.cepal.org/es/temas/proyecciones-demograficas/estimaciones-proyecciones-excel $>$ [acceso 10/12/2020].

CELADE (s. f.). Investigación de la Migración Internacional en Latinoamérica (IMILA) [en línea]. s. 1.: CEPAL. Disponible en: <https://celade.cepal.org/ bdcelade/imila> [10/12/2020].

Comisión Económica para América Latina y el Caribe (CEPAL) (2019). América Latina y el Caribe: Estimaciones y proyecciones de población [en línea]. Disponible en: <https://www.cepal.org/es/temas/proyecciones-demograficas/estimaciones-proyecciones-poblacion-total-urbana-rural-economicamente-activa $>$ [acceso 10/12/2020]. 
Comisión Económica para América Latina y el Caribe (CEPAL) (1998). Información básica sobre el sector agropecuario de la subregión norte de América Latina y el Caribe [documento mimeografiado]. Ciudad de México: CEPAL.

Costa Rica, Poder Legislativo (1961). Ley n.o 2762, de Régimen de Relaciones de Productores, Beneficiadores y Exportadores de Café, 21 de junio. Disponible en: <http://www.pgrweb.go.cr/scij/Busqueda/Normativa/Normas/nrm_texto_completo.aspx?nValor $1=1 \&$ nValor2 $=36867>$ [acceso 28/02/2021].

Costa Rica, Poder Legislativo (1990). Ley n.o 7147, de Creación de la Corporación Bananera Nacional (CORBANA), 30 de abril. Disponible en: $<$ http:// www.pgrweb.go.cr/scij/Busqueda/Normativa/Normas/nrm_texto_completo.aspx param $1=\mathrm{NRTC} \& \mathrm{nValor} 1=1 \&$ nValor $2=10009 \&$ nValor $3=10712 \& \mathrm{st}$ rTipM=TC $>$ [acceso 28/02/2021].

Deere, C. D. y M. León (2002). Género, propiedad y empoderamiento: tierra, Estado y mercado en América Latina. Quito: 1M Editores, Programa Universitario de Estudios de Género, Universidad Nacional Autónoma de México, FLACSO-Ecuador.

Delgado, M. (2020). Migrantes con arraigo tendrán permisos de trabajo. San Carlos Digital [en línea], 23 de junio. Disponible en: $<$ https://sancarlosdigital.com/migrantes-con-arraigo-tendran-permisos-de-trabajo/> [acceso 28/02/2021].

Dirección General de Migración y Extranjería de Costa Rica (2020). Informes estadísticos anuales. San José: Dirección General de Migración y Extranjería. Disponible en: <https://www.migracion.go.cr/Paginas/Centro\%20de\%20 Documentaci\%C3\%B3n/Estad\%C3\%ADsticas.aspx $>$ [acceso 25/02/2021].

Edelman, M. (2019). Campesinos contra la globalización: movimientos sociales rurales en Costa Rica. San José: UCR.

Estrategia Nacional de Involucramiento (s. f.). Boletines de Monitoreo de Tierra [en línea]. Managua: Nitplan. Disponibles en: <https:/www.nitlapan.org.ni/ boletines/> [acceso 12/12/2020].

EFE (2020). Nicaragua y Costa Rica firman un acuerdo laboral para más de 20.000 trabajadores. Portal EFE [en línea], 7 de noviembre. Disponible en: $<$ https:// www.efe.com/efe/america/economia/nicaragua-y-costa-rica-firman-unacuerdo-laboral-para-mas-de-20-000-trabajadores/20000011-4388283> [acceso 10/12/2020]. 
Flores, B. (2019). ¿Puede la agricultura nacional sobrevivir sin mano de obra extranjera? La República [en línea], 8 de mayo. Disponible en: https:/www. larepublica.net/noticia/puede-la-agricultura-nacional-sobrevivir-sin-manode-obra-extranjera $>$ [acceso 24/02/2021].

Fundación Internacional para el Desafío Económico Global (FIDEG) (2017). Encuesta de Hogares para la Medición de la Pobreza en Nicaragua-Informe de resultados 2017 [en línea]. Disponible en: <http://fideg.org/investigaciones-y-publicaciones/resultados-la-encuesta-hogares-la-medicion-la-pobreza-en-nicaragua-informe-resultados-2017/> [acceso 15/11/2020].

González, M. A. (2021). Gobierne miente sobre control de migrantes en fincas agrícolas. Diario Extra [en línea], 27 de enero. Disponible en: <https:// www.diarioextra.com/Anterior/detalle/440190/gobierno-miente-sobre-control-de-migrantes-en-fincas-agr-colas $>$ [acceso 29/01/2021].

Herrera, J. J. (2019). Peones extranjeros sostienen más del 70\% de la agricultura y del 50\% de la construcción tica. Telemática [en línea]. San José: Telemática. Disponible en: <https://www.teletica.com/nacional/peones-extranjeros-sostienen-mas-del-70-de-la-agricultura-y-del-50-de-la-construcciontica_227617> [acceso 14/02/2021].

International Coffee Organization (ICO) (s. f.). Datos históricos. International Coffe Organization [en línea]. Disponible en: <http://www.ico.org/es/new historical_c.asp?section=Estad\%EDstica $>$ [acceso 15/01/2020].

Instituto de Investigaciones en Ciencias Económicas (IICE) (2007). Historia económica de Costa Rica en el siglo XX [proyecto de investigación]. San José: Universidad de Costa Rica.

Instituto Nacional de Estadística y Censos (INEC)-Costa Rica (s. f.). Encuesta Continua de Empleo (ECE), varios trimestres [en línea]. Disponible en: <sistemas.inec.cr:8080/bininec/RpWebEngine.exe/ Portal?BASE $=$ ECE\&lang $=$ esp $>$ [acceso 15/01/2020].

Instituto Nacional de Estadística y Censos (INEC)-Costa Rica (2019). Encuesta Nacional de Hogares (ENAHO). San José: INEC.

Instituto Nacional de Estadística y Censos (INEC)-Costa Rica (2020). Encuesta Nacional de Hogares (ENAHO). San José: INEC.

Instituto Nacional de Estadística y Censos (INEC)-Costa Rica (2014). Censo Agropecuario. San José: INEC. 
Instituto Nacional de Estadística y Censos (INEC)-Costa Rica (2006). Encuesta de Hogares de Propósitos Múltiples. San José: INEC.

Instituto Nacional de Estadística y Censos (INEC)-Costa Rica (s. f.). Censos de Población 1973, 1984, 2000, 2011. San José: INEC.

Instituto Nacional de Estadísticas y Censos (INEC)-Nicaragua (2003). Perfil comparativo de la pobreza en Nicaragua (1993-2001). Managua: INEC. Disponible en: <https://www.inide.gob.ni/docs/bibliovirtual/publicacion/ comppobreza.pdf $>$ [acceso 10/01/2021].

Instituto Nacional de Información de Desarrollo (INIDE)-Nicaragua (s. f.). Anuario estadístico, varios años. Managua: INIDE.

Instituto Nacional de Información de Desarrollo (INIDE)-Nicaragua (2011). Censo Agropecuario. Managua: INIDE.

Instituto Nacional de Información de Desarrollo (INIDE)-Nicaragua (s. f.). Censos de Población 1971 y 2005. Managua: INIDE.

Instituto Nacional de Información de Desarrollo (INIDE)-Nicaragua y Ministerio Agropecuario y Forestal (MAGFOR) (2012). Informe final IV Censo Nacional Agropecuario. Managua: INIDE y MAGFOR. Disponible en: $<$ http://www.fao.org/3/I9362ES/i9362es.pdf> [acceso 10/11/2020].

Jiménez Flores, J. C. (2020). Más de 13.000 trabajadores con arraigo dedicados a labores agro han solicitado su regularización. InfoAgro Costa Rica [en línea], 23 de septiembre. Disponible en: <http://infoagrocr.blogspot.com/2020/09/ mas-de-13000-trabajadores-con-arraigo.html $>$ [acceso 23/02/2021].

Lang Oreamuno, E. M. (2020). Costa Nica: Ser nicaragüense en Costa Rica durante el COVID-19. Delfino [en línea], 3 de agosto. Disponible en: $<$ https:// delfino.cr/2020/08/costa-nica-ser-nicaraguense-en-costa-rica-durante-elcovid-19> [acceso 14/02/2020].

León Sáenz, J. y G. Peters Solórzano (2017). Historia económica de Costa Rica en el siglo XX. Tomo II. San José: UCR. Disponible en: <http://www.iice. ucr.ac.cr/LIBROS/Economia \%20rural.pdf> [acceso 10/11/2020].

Ministerio de Planificación Nacional y Política Económica de Costa Rica (MIDEPLAN) (2018). Regiones de Planificación [mapa]. San José: Ministerio de Planificación Nacional y Política Económica [en línea]. Disponible en: $<$ https://documentos.mideplan.go.cr/share/s/eZ8HYuxgT16xCHx3ZAE$\operatorname{Brg}>$ [acceso 05/05/2021]. 
Ministerio de Agricultura y Ganadería de Costa Rica (2020). Resolución 42406. San José: Ministerio de Agricultura y Ganadería, 22 de junio.

Morales, N. y R. Segura (2017). Distribución de la tierra y su relación con la desigualdad social. Simposio del Censo Nacional Agropecuario 2014 [en línea]. Ponencia preparada para el Simposio del Censo Nacional Agropecuario 2014. Disponible en: < http://estadonacion.or.cr/files/biblioteca_virtual/022/Equidad/SimposioCENAGRO.pdf> [acceso 06/12/2020].

Observatorio Geográfico en Salud (OGES) (s. f.). Ministerio de Salud. OGES [en línea]. Disponible en: <geovision.uned.ac.cr/oges/visores/catalogo/ establecimientos_y_servicios/ministerio_de_salud.html $>$ [acceso 06/12/2020].

Oficina Ejecutiva de los Censos (1972). Censo Agropecuario de 1971, cifras preliminares. Managua: documento mimeografiado, archivo personal del autor.

Organización de las Naciones Unidas para la Alimentación y la Agricultura (FAO) (s. f. a). Cultivos y productos de ganadería. FAOSTAT [en línea]. s. 1.: FAO. Disponible en: <http://www.fao.org/faostat/es/\#data/TP $>$ [acceso 08/12/2020].

Organización de las Naciones Unidas para la Alimentación y la Agricultura (FAO) (s. f. b). Línea de trabajo sobre desarrollo económico y social. FAO [en línea]. s. 1.: FAO. Disponible en: <http://www.fao.org/economic/es-home/es/\#.X7SIvNu23OQ $>$ [acceso 07/12/2020].

Organización Internacional del Trabajo (OIT) (2021). Perspectivas sociales y del empleo en el mundo [en línea]. s. 1.: OIT. Disponible en: <https://www.ilo. org/wesodata/> [acceso 20/04/2021].

Organización para la Cooperación y el Desarrollo Económicos (OCDE) (2018). Estudios Económicos de la OCDE [en línea]. OCDE: Costa Rica. Disponible en: <http://www.oecd.org/economy/surveys/Costa-Rica-2018-EstudiosEconomicos-de-la-OCDE.pdf $>$ [acceso 08/12/2020].

Oviedo, A. M.; S. Sánchez; K. Lindert y H. López (2015). El modelo de desarrollo de Costa Rica. De bueno a excelente [en línea]. Washington: Banco Mundial. Disponible en: < https://openknowledge.worldbank.org/bitstream/ handle/10986/22023/K8319-SP.pdf> [acceso 07/12/2020].

Picado, W. y E. Botella (2017). Tenencia de la tierra y cambio territorial en Costa Rica (1950-2015). XII Congreso Internacional de la Asociación Española de Historia Económica [en línea], 6 al 9 de setiembre, Salamanca, España. Disponible en: <https:/www.researchgate.net/publication/319632403_Te- 
nencia_de_la_tierra_y_cambio_territorial_en_Costa_Rica_1950-2015> [acceso 09/12/2019].

Pomareda, C. (2018). Pobreza en las propuestas de los candidatos para el desarrollo nacional. El Mundo, 10 de enero. Disponible en: <https://www. elmundo.cr/opinion/pobreza-las-propuestas-los-candidatos-desarrollo-nacional/> [acceso 15/12/2020].

Programa de las Naciones Unidas para el Desarrollo (PNUD) (2019). $2019 \mathrm{Hu}$ man Development Index Ranking. s. 1.: PNUD.

Reena, S. (2020). Rainforest Alliance certifica fincas de piña poco éticas, afirman activistas. Federación Ecologista [en línea]. Disponible en: <https://feconcr.com/agronegocios/rainforest-alliance-certifica-fincas-de-pina-poco-eticas-afirman-activistas/> [acceso 10/01/2021].

Secretaría Ejecutiva de Planificación Sectorial Agropecuaria (SEPSA) (2020). Comercio exterior del sector agropecuario. Enero-setiembre 2019-2020. San José: SEPSA. Disponible en: <http://www.sepsa.go.cr/DOCS/2020-021-Comercio_Exterior_Enero-Setiembre_2019-2020.pdf> [acceso 14/02/2021].

Siu Lanzas, M. (2020). Intensifican controles mano de obra migrante. Diario Extra [en línea], 28 de diciembre. Disponible en: $<$ https://www.diarioextra.com/Anterior/detalle/437544/intensifican-control-por-mano-de-obramigrante-> [acceso 20/02/2020].

Tomei, J. (2015). The Sustainability of Sugarcane-Ethanol Systems in Guatemala: Land, Labour and Law. Elsevier Biomass and Bioenergy, 82, pp. 94-100.

Voorend, K.; Anker, R. y Anker, M. (2017). Informe sobre living wage. Zonas rurales de Costa Rica. Provincias de Limón (regiones de Guápiles, Guácimo, Siquirres y Matina) y Heredia (región de Puerto Viejo de Sarapiquí). Coalición Global de Salario Digno (Global Living Wage Coalition) [en línea], 1(19). Disponible en: <https://www.globallivingwage. org/wp-content/uploads/2019/01/Costa-Rica-Informe-sobre-living-wage ESPAN\%CC\%83OL-final.pdf $>$ [acceso 12/12/2020].

\section{Contribución de autoría}

Este trabajo fue realizado en su totalidad por Eduardo Baumeister. ${ }^{46}$

46 Se agradecen los comentarios de dos revisores anónimos a una versión previa de este documento, que permitieron mejorar la presentación. 